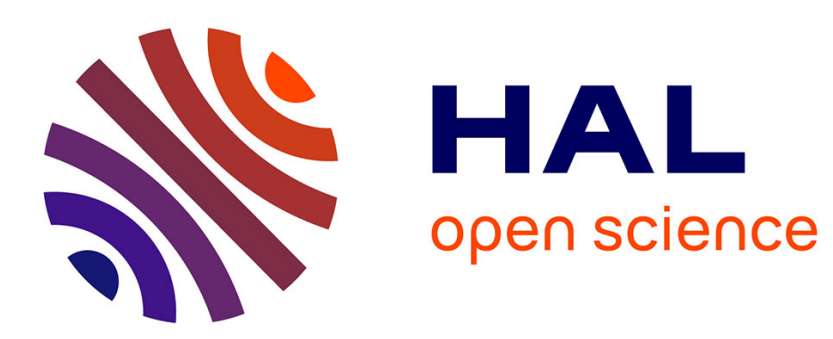

\title{
A business repository enrichment process: A case study for manufacturing execution systems
}

\author{
Ikbal Arab-Mansour, Pierre-Alain Millet, Valérie Botta-Genoulaz
}

\section{To cite this version:}

Ikbal Arab-Mansour, Pierre-Alain Millet, Valérie Botta-Genoulaz. A business repository enrichment process: A case study for manufacturing execution systems. Computers in Industry, 2017, 89, pp.13 - 22. 10.1016/j.compind.2017.03.006 . hal-01533642

\section{HAL Id: hal-01533642 \\ https://hal.science/hal-01533642}

Submitted on 6 Jun 2017

HAL is a multi-disciplinary open access archive for the deposit and dissemination of scientific research documents, whether they are published or not. The documents may come from teaching and research institutions in France or abroad, or from public or private research centers.
L'archive ouverte pluridisciplinaire HAL, est destinée au dépôt et à la diffusion de documents scientifiques de niveau recherche, publiés ou non, émanant des établissements d'enseignement et de recherche français ou étrangers, des laboratoires publics ou privés. 


\title{
A business repository enrichment process: A case study for manufacturing execution systems
}

\author{
Ikbal Arab-Mansour, Pierre-Alain Millet*, Valérie Botta-Genoulaz \\ Univ Lyon, INSA-Lyon, DISP EA 4570, F-69621, Villeurbanne, France
}

\section{A R T I C L E I N F O}

\section{Article history:}

Received 5 October 2016

Received in revised form 7 February 2017

Accepted 30 March 2017

Available online xxx

\section{Keywords:}

Manufacturing execution system (MES)

Information system alignment

ISO/IEC 62264

SCOR model

Interoperability

Integration

Heterogeneity

\section{A B S T R A C T}

A key characteristic of the software applications supporting manufacturing business processes is their heterogeneity. This is due not only to differences in their development and deployment, but also to the variety of processes and actors in complex organizations. Heterogeneity at the semantic level is one of the major problems in any process of interoperability and/or integration. There is therefore a need for developing new approaches and methods to ensure interoperability between different software solutions. In the context of a case study with a consortium of MES (Manufacturing Execution Systems) publishers, we propose a semantic alignment process of repositories used in the construction of a MES solution called “MES On Demand”, using multiple applications and driven by business processes. Through the study of semantic heterogeneities, we use an enrichment-based alignment for business repositories applied to ISO/IEC 62264. Finally, we evaluate the contribution of this approach to enterprise maturity in the application of standards and reference models, using Nascio's Enterprise Architecture Maturity Model. This proposal, which is useful for practitioners and experts, is a contribution to academic study on semantic alignment for master interoperability.

(c) 2017 Elsevier B.V. All rights reserved.

\section{Introduction}

Market requirements are constantly evolving and are demanding that companies seek new solutions and techniques to build information systems (IS) in line with their needs and strategies. Enterprise IS are often composed of several business applications such as Enterprise Resource Planning (ERP) systems, Manufacturing Execution Systems (MES), and Product Lifecycle Management (PLM) systems. A result of this trend is the need for companies' "integration". Integration can be seen as a process consisting in high levels of interaction between people, machines and applications, which enhances the synergy within a company [1]. Regarding IS, integration essentially involves the application's components. In some cases, components are loosely coupled to preserve their heterogeneity and autonomy. This is called the "interoperability" of applications, which is one way to facilitate integration.

\footnotetext{
* Corresponding author.

E-mail addresses: ikbal.mansour@insa-lyon.fr (I. Arab-Mansour), pierre-alain.millet@insa-lyon.fr (P.-A. Millet), valerie.botta-genoulaz@insa-lyon.fr (V. Botta-Genoulaz).
}

Many projects and studies have been carried out to develop and design new approaches and corporate architectures in order to ensure the interoperability of systems at the technical and semantic levels. The service-oriented approach provide sound answers to the problems of technical interoperability. Indeed, it is essential that business applications remain capable of consistent interpretation of the data exchanged and the functions used. Semantic conflicts may arise during the exchange between applications. These conflicts may involve not only data [2] but also the business logic of applications [3]. It becomes vital to identify resulting conflicts and proceed to their resolution as soon as possible, preferably in the early stages of an integration project. The resolution of these semantic heterogeneities requires mechanisms to determine the correspondence areas and/or semantic conflict between applications.

Current research on semantic alignment uses mainly ontologies. Most of these ongoing development initiatives affirm that automation of alignment is difficult to achieve, and highlight the role of users in the validation of semantic alignment [4]. The semantic alignment between applications therefore remains an unresolved issue in the context of integration and systems interoperability, which requires an alignment process. Consequently, the role of experts in integration projects is critical. As business applications are based on either proprietary or 
standard business repositories, a way to tackle this research issue is to provide semantic alignment solutions for business repositories. In this paper we present a case study where a new alignment methodology enriches a given business repository by other business repositories. It provides experts with an assisted process of unidirectional semantic alignment of business repositories, using semantic check rules to help them solve any semantic heterogeneity problems that may exist between several business sources.

This case study is the result of an industrial initiative conducted by a consortium of manufacturing software publishers. They launched a "MES on demand" platform, using services from various packages, including Manufacturing Execution Systems (MES) and Supply Chain Execution (SCE). To allow such an "on-demand" MES to manage heterogeneity between the trades, software packages, and business reference models involved in the project, we formalize the knowledge of business processes and business objects that will be supported by applications and their interactions. Of course, this knowledge is implemented in different ways and often partially in each software package.

The capacity to build an "on demand" multi-publisher MES solution depends on the capacity to align business repositories, companies' needs, and functional layer components, which contains heterogeneous knowledge for the following reasons:

a Several software packages are more often involved and are heterogeneous;

b Industrial companies' requirements are expressed in their own business language and have to be mapped onto the repository language;

c Finally, the capacity to link a standard business repository and a standard web service of applications is a condition for mastering the implementation of the industrial company's business model in an orchestration of existing web services.

More often, aligning two structures (models, standards, etc.) means that for each entity (e.g. concepts and relationships) in the first structure, we try to find a corresponding entity that has the same meaning in the second structure [5]. However, in a projectoriented approach, the aim is to build a common repository for all consortium members, which focuses on a certain scope and aim of the project. In contrast to the approaches seeking for a complete and generic alignment, we propose to master the heterogeneity derived from business reference models, which are partially applied. We therefore propose to seek neither to modify the structure of one of the repositories nor to merge them. We create a new version $V_{i+1}$ of a given business repository $V_{i}$ considered as Reference Repository by adding some elements or some semantic relationships from a second business repository "A", depending on the level of granularity or consistency.

We applied this methodology in our case study with MES business repository IEC/ISO 62264, which has been enriched by the Supply Chain Operation Reference (SCOR) model. We then implemented it the ARIS SOA Architect platform.

The remainder of this paper is organized as follows. Section 2 introduces the literature review in terms of techniques and approaches related to enterprise modelling, business repositories and systems' interoperability. The alignment methodology, the enrichment process, and its implementation are presented in Section 3. In Section 4, we evaluate the methodology using an Enterprise Architecture Maturity Model based on a set of practices. Finally, we draw some conclusions for firms and outline some directions for future research, in Section 5.

\section{Literature review}

Most information systems (IS) contain several applications to meet several business needs, According to Refs. [3] and [6], the main characteristics of a company's applications are autonomy, distribution and heterogeneity. There are various levels of heterogeneity, including technical, syntactic and semantic. In this paper, we focus on the problems of heterogeneity of enterprise applications, particularly at the semantic level, which is one of the major problems in any interoperability and/or integration process. According to the European Interoperability Framework [7], there are three aspects of interoperability: (i) organizational, (ii) technical, and (iii) semantic. The different aspects of interoperability emphasize the fact that the heterogeneity of IS in data, applications or process levels makes the implementation of interoperability between IS more difficult. This complexity creates new strategies, methods and architectures for the design of IS to be qualified as interoperable.

After an introduction on the alignment issue and a brief survey on enterprise modelling and modelling frameworks, the remainder of this section presents the two main repositories that form the basis of this research work, the IEC/ISO 62264 repository and the SCOR model.

\subsection{Interoperability vs alignment}

This issue of interoperability and heterogeneity is crucial for MES when manufacturing resources, processes, and control methods are heterogeneous. The Manufacturing Enterprise Solutions Association proposes a formal definition [8]. MES is one of the software solutions used to bridge production planning and equipment control systems. To meet the needs of a variety of manufacturing environments, they identified 11 main functions, some directly linked to the process, and others described as cross functions.

The academic research on integration problems points out the importance of the integration with other information systems. Ref. [9] propose a service-oriented framework to address reconfigurability required by changing business environments. Ref. [10] present a literature review of MES systems, showing several considerations on commercial solutions, and major issues related to their use and implementation. These authors report on in-depth discussions on the research areas that would have to be explored in order to resolve the increased complexity of MES systems.

A well-known business standard for MES is the ISA-95 standard published by the Instrumentation, Systems \& Automation (ISA) Committee. An academic version has been published as the IEC/ISO 62264. This standard deals with the formalization of exchange, around the manufacturing system, with other areas of the company. Its function model puts the manufacturing control function in a central position, intermediary between the various departments of the company. ISA-95 is widely adopted by market players for the design of information flows between shop floor applications and those at a higher level. It also allows the industry to have a consistent terminology. MES are used, inter alia, by the aerospace, automotive, semiconductor, optoelectronic, pharmaceutical and petrochemical industries [11-13,41].

Both MESA and ISA organizations highlight the diversity of software capabilities required, with software packages covering different manufacturing domains that often overlap. Semantic alignment is then a major challenge for MES projects for companies. 


\subsection{Enterprise modelling and modelling frameworks}

Enterprise Modelling (EM) can be defined as a means for capturing and capitalizing on the knowledge of a company and its different aspects: functional, informational, structural, behavioural, organizational or other [1]. Ref. [14] proposes a classification of these modelling methods: operational methods such as GIM [15] or IS and process-oriented methods such as Olympios [16]; reference architecture-based methods such as CIM-OSA (Computer Integrated Manufacturing, Open System Architecture) $[17,18]$ or ARIS (ARchitecture for integrated Information Systems) [19], or S-BEAM that supports decisions at both strategic and operational levels, using the SCOR model [20].

An enterprise-modelling framework identifies the information types and their relationships to model a company by organizing them into logical structures. The ENV 12204 standard [21] has proposed an initial specification of the main elements for the modelling of "constructs", and the ISO 15704 [22] defines the requirements for building an enterprise reference architecture. These requirements were included in the CEN/ISO 19439 (Enterprise Integration Framework for enterprise modelling) standard [23] that proposes a modelling framework with three dimensions: life cycle of models, view of models, and genericity. Another standard is the CEN/ISO 19440 [24] which has adopted the modelling constructs defined in the ENV 12204 standard, and which complies with the three dimensions defined in the ISO 19439 standard.

\subsection{Standards and business repositories for the enterprise}

Repositories exist in medical emergencies, entrepreneurship, professional skills, and so on. There are many standards and business repositories in manufacturing, particularly those used by Manufacturing Execution Systems.

The subcommittee 65A established the IEC/ISO 62264 international standard [25-27], based on the American standard ANSI/ISA-95. It defines four domains: production, quality, maintenance and inventory. The fundamental concept of the IEC/ISO 62264 standard is based on the breakdown of business and control functions into sub-processes and activities. The activities use inputs and produce information objects. Information flows between functions are represented by the content of their interfaces. Table 1 shows the attributes of the Equipment Property class.

The activities defined in the IEC/ISO 62264 standard are used to provide activity models that can be adapted and customized according to business needs.
The Supply Chain Operation Reference (SCOR) model provided by the Supply Chain Council [28] offers a vision and an approach that focuses on business processes within the supply chain. In Version 9.0 [28], the SCOR model contains 27 key processes detailed in 171 process elements, 274 pieces of information defined as inputs/outputs for process elements, 489 best practices, and 498 metrics. The SCOR model is based on four levels: 1-strategic, 2-tactical, 3-operational, and level 4, which is not formalized in the model. Ref. [29] has proposed a classification of the information exchanged in the SCOR model. He has identified ten classes of information (actor, rules, plan, object, resource, condition, decision, flow, journal, and metric), as well as several studies based on the SCOR model, used to develop methods, knowledge bases [30] and tools for the integration [31], evaluation [32] and alignment [33] of supply chains. MES are present in the SCOR model through various features: production, maintenance and inventory.

There are other standards related to MES applications, such as:

- STEP (Standards for the Exchange of Product data), or ISO 10303 [34], which is a product-oriented standard for product data exchange between applications;

- ISO 9001, which is a quality-oriented standard. The version 2000 promotes the adoption of a process approach while developing, implementing and improving the effectiveness of a quality management system, to enhance customers' satisfaction by complying with their requirements [35];

- AFNOR, which defined a maintenance-oriented standard (13306 X 60-319) in 2001. Maintenance management represents one of the functional domains of the IEC/ISO 62264 standard.

This diversity and heterogeneity of business repositories for MES highlight the need for a new alignment approach to help practitioners to use some of these repositories when assembling heterogeneous components to build their IS.

\section{The MES business repository case study}

In the following, we present the methodology used to enrich the IEC/ISO 62264 MES repository $\left(\mathrm{V}_{\mathrm{i}}\right)$ by the SCOR model $(\mathrm{A})$. This enrichment is composed of the following steps:

(i) the comparison between the two business repositories $V_{i}$ and A,

(ii) the extraction and the modelling of the contents to be aligned, (iii) the semantic alignment process,

(iv) and the validation cycle.

Table 1

The Attributes of the Equipment Property Class (IEC 62264-2).

\begin{tabular}{|c|c|c|}
\hline Attribute Name & Description & Examples \\
\hline ID & An identification of the specific property & $\begin{array}{l}\text { Equipment name } \\
\text { Run rate } \\
\text { Template size }\end{array}$ \\
\hline Description & Additional information about the equipment property & $\begin{array}{l}\text { "Local name for the widget machine" } \\
\text { "Widget making average run rate" } \\
\text { "Widget jig template size" }\end{array}$ \\
\hline Value & $\begin{array}{l}\text { The value, set of values, or range of the property. } \\
\text { The value(s) is assumed to be within the range of set of defined values for the related equipment property. }\end{array}$ & $\begin{array}{l}\text { Big Bertha } \\
59 \\
300\end{array}$ \\
\hline Value unit of measure & The unit of measure of the associated property value, if applicable. & $\begin{array}{l}\text { [not applicable] } \\
\text { Widgets/h } \\
\mathrm{cm}\end{array}$ \\
\hline
\end{tabular}


We detail each of these steps through illustrations with ARIS models. The ARIS platform [19], which is independent of the consortium members, allows the modelling of business processes and objects and the use of semantic rules and scripts to analyse these models.

\subsection{Comparison between repositories}

This step helps to assess the degree of similarity and heterogeneity between the different business models of the two repositories $V_{i}$ and $A$. There are four heterogeneity levels [36]: (i) syntactic; (ii) terminological; (iii) conceptual; (iv) pragmatic.

The syntactic level relates to knowledge description languages used to represent the different models of the two repositories. In our case, the ISO/IEC 62264 standard exists in a textual form that describes the various concepts, object models, etc., and a digital form represented by XML files B2MML "Business to Manufacturing Markup Language" [37] to describe the interaction between MES and ERP systems. The SCOR model exists in a textual form proposed by the Supply Chain Council that describes the contents of the various processes, and a digital form represented by models using the ARIS language. Comparing the two versions of both textual repositories, we see a clear difference in the lexicon used. This difference is due to the diversity of the committees that create both standards and their differing scope. When comparing the two digital formats, it is clear that the concepts are quite different, since the ISO/IEC 62264 describes the exchanged information flows while the SCOR model describes the processes of the supply chain.

The terminological level concerns the identification of functions, business objects and processes. It is possible to identify the following typical conflicts like synonymy, polysemy and syntactic variations of the same word (abbreviations, etc.).

The conceptual heterogeneities involve differences in:

- Coverage: the ISO/IEC 62264 covers production, maintenance, quality and inventory domains, while the SCOR model is designed and maintained to support supply chains with various complexities and across multiple industries;
- Granularity: the entities of the two business repositories describe real objects in various degrees of detail;

- Perspective: the two business repositories cover different points of view.

The pragmatic level concerns the heterogeneous interpretation of the repositories. These problems can occur when experts or different communities interpret different repositories in different contexts. Indeed, this level is quite complex, since the result of the alignment can change, depending on the interpretations of the two repositories. Table 2 shows a comparative study of the ISO/IEC 62264 and the SCOR model, applied to the MES domain and classified according to four levels of heterogeneity.

\subsection{Extraction and modelling of content to be aligned}

The first step is to choose the business content from repository A to align it with the MES repository $V_{i}$, depending of the objectives of partners in the context of our case study, which influences the scope of expected alignment. The main purpose is to reduce the coverage issues identified in the comparison phase, and to choose only the content close to the MES domain from a business point of view. Parts of the content of the repository A can be removed from the alignment process. This choice is usually made by business experts in order to meet specific business needs. In our case study, we restrict the alignment to the MES domain as defined by ISO/IEC 62264 , excluding the parts of the second reference that is out of the domain. More precisely, we keep only the MAKE process of the SCOR model, which includes the MES functions and objects. We have identified 28 process elements and 107 pieces of information that can be used. The choice of MAKE process' content is based on the results of Ref. [29].

The modelling of the extracted content ensures a single reading of the models of the two business repositories. This is done using a simplified modelling framework based on the ISO 19439 standard [23] focused on modelling constructs required by the ISO 62264 repository. In this simplified framework, the repository level is an aggregation of the 'generic' and "partial" levels of the ISO 19439

Table 2

Results of comparison step between ISO/IEC 62264 and the SCOR model.

\begin{tabular}{|c|c|c|c|}
\hline & & ISO/IEC 62264 & SCOR model \\
\hline \multirow[t]{2}{*}{$\begin{array}{l}\text { Syntactic } \\
\text { level }\end{array}$} & $\begin{array}{l}\text { Description } \\
\text { language }\end{array}$ & $\begin{array}{l}\text { - Textual } \\
\text { - Digital (B2MML) }\end{array}$ & $\begin{array}{l}\text { - Textual } \\
\text { - Digital (ARIS models) }\end{array}$ \\
\hline & Concepts & Information, Activities & $\begin{array}{l}\text { Processes and process elements, Inputs/Outputs, } \\
\text { Metrics, Best practices }\end{array}$ \\
\hline \multirow[t]{3}{*}{$\begin{array}{l}\text { Terminological } \\
\text { level }\end{array}$} & $\begin{array}{l}\text { Presence of } \\
\text { Synonymy }\end{array}$ & Yes & Yes \\
\hline & $\begin{array}{l}\text { Presence of } \\
\text { Polysemy }\end{array}$ & Yes & Yes \\
\hline & $\begin{array}{l}\text { Presence of } \\
\text { Syntactic } \\
\text { variations }\end{array}$ & Yes & Yes \\
\hline \multirow[t]{4}{*}{$\begin{array}{l}\text { Conceptual } \\
\text { level }\end{array}$} & Coverage & MES & $\begin{array}{l}\text { Supply chain operations } \\
\text { Several applications, of which MES }\end{array}$ \\
\hline & & $\begin{array}{l}\text { - Production } \\
\text { - Maintenance } \\
\text { - Quality } \\
\text { - Inventory }\end{array}$ & \\
\hline & Granularity & Weak & Varies according to the levels \\
\hline & Perspective & Informational, Functional & $\begin{array}{l}\text { Processes, performance management of the supply } \\
\text { chain }\end{array}$ \\
\hline $\begin{array}{l}\text { Pragmatic } \\
\text { level }\end{array}$ & \multicolumn{3}{|c|}{ Varies according to the interpretation of the semantic content of each repository } \\
\hline
\end{tabular}


standard, while the project level used to model client requirements and systems is the implementation of the "particular" level of the standard. Likewise, we use only the informational and functional views of the standard, excluding the organizational and resource views, because the ISO 62264 standard defines only data and function models. Regarding the lifecycle phase dimension of the ISO 19439 standard, we focus on the "concept definition" and "requirement" phases. The business and functional models in the genericity dimension at the repository level are then considered in the "concept definition" phase, whereas at the project level, they are considered in the "requirement" phase. This ensures the conformity of models created in this framework with the generic level, and then for the industrial companies, with the MES repository.

The purpose of this framework is to model these heterogeneous repositories using the same constructs and a certain syntactic interoperability between them. We thus propose some solutions for problems of heterogeneity, regarding syntax.

Given the large number of SCOR elements to be modelled, we use the "matrix models" of the ARIS platform to represent the relationships between the functions ( 28 process elements) and their inputs/outputs (107 inputs/outputs). Fig. 1 shows an excerpt from an overview of the matrix, which is representative of the MAKE process, with the input/output (considered as business objects modelled using the ARIS object type "clusters") in lines and the functions in columns.

\subsection{Semantic alignment process}

This process concerns the definition of semantic relationships between business repositories. The content extraction step reduces coverage problems. However, it is difficult to find the right granularity to align the two repositories. On the one hand, a "highlevel" alignment (top-down) may not provide enough information on the differences and similarities; on the other hand, a "very low" (bottom-up) alignment is not an easy task, given the large number of potential connections between the two repositories. We propose to analyse the level of granularity in both repositories, by examining separately the elements of each view defined in the modelling framework. This implies the creation of semantic relationships between the elements of each view. Reasoning independently in each view is a simplification factor, which reduces the number of elements and therefore the number of connections. However, this independence can lead to semantic inconsistencies in the relations between the views. We tackle this point in Section 3.4, in which we propose solutions based on semantic control rules.

In Fig. 2, we show an example of a relationship (specialization relation) between the two constructs "Repository Business Activity" and "Repository Business Operation". This relationship is reflected in the alignment step by one or more semantic relationships between entities in the two repositories. The example therefore contains two types of semantic relation: "Equivalent to" (corresponds-to) and "Belonging to" (a sub-state) between a function of ISO/IEC 62264 "Tracking Operations" and three functions of the SCOR model. Regarding the difference in perspective (functional vs processes), it contributes to enriching the MES repository by creating new semantic relationships. We have added a new relationship (Is_predecessor) between the functions of the SCOR model belonging to the same process element. In the following, we propose a "hybrid" semantic alignment approach, which is both top-down and bottom-up.

\subsubsection{Informational view}

The ISO/IEC 62264 standard defines only nine object models. We can classify these object models in two main categories: common object models ("Common Object Models"), and object models for the management of manufacturing operations ("Operations Management Information"). The purpose of this classification is, firstly, to reduce the risk, the cost and the errors associated with the implementation of these interfaces, and secondly, to provide a semantic level allowing other standards or repositories to adapt. Regarding the informational view of the SCOR model, we identify in the "MAKE" process 140 objects defined as inputs/outputs of process elements. We propose a classification of these elements into five classes (Resource, Object,

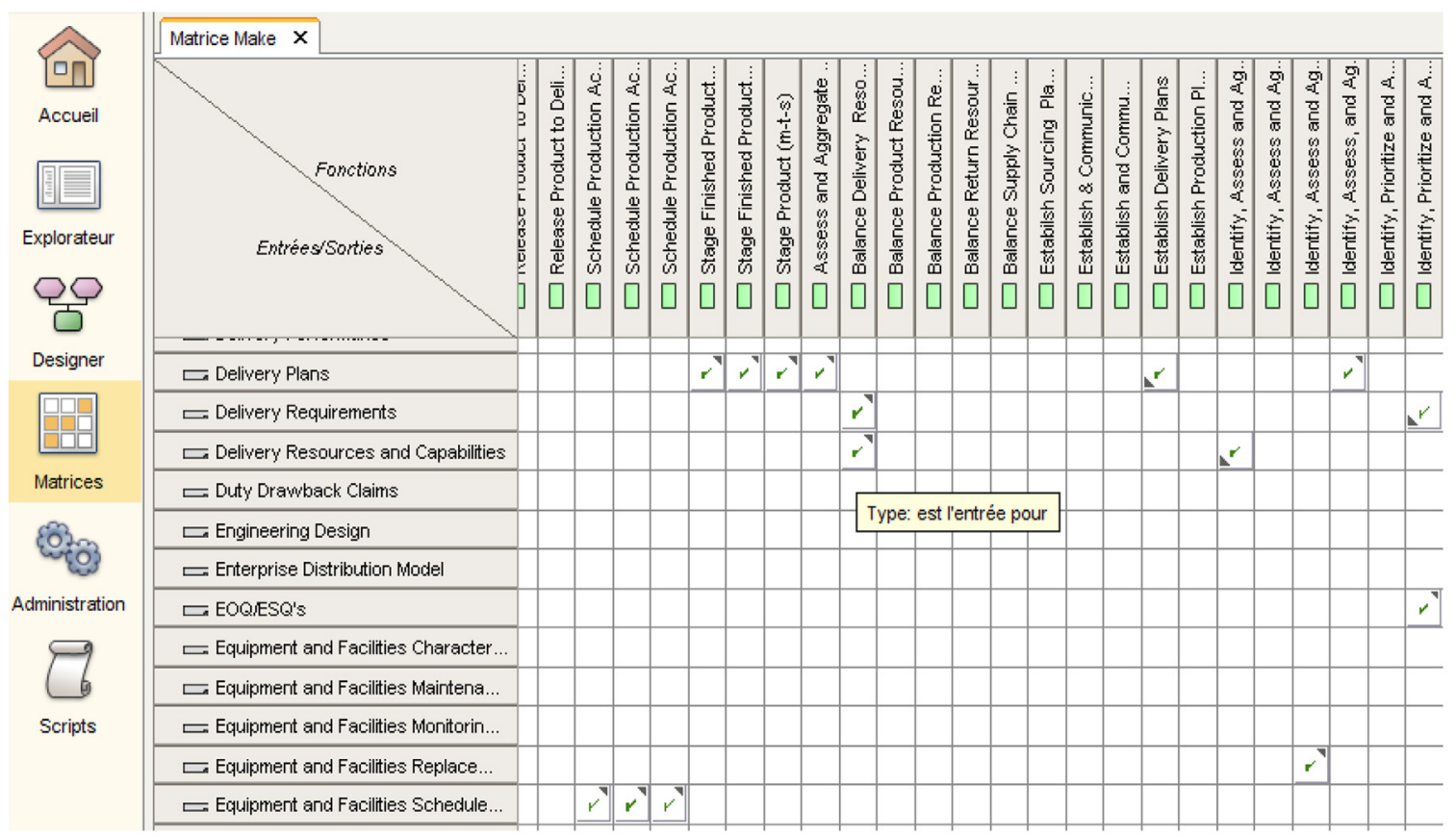

Fig. 1. Example of the alignment modelled by means of an ARIS matrix. 


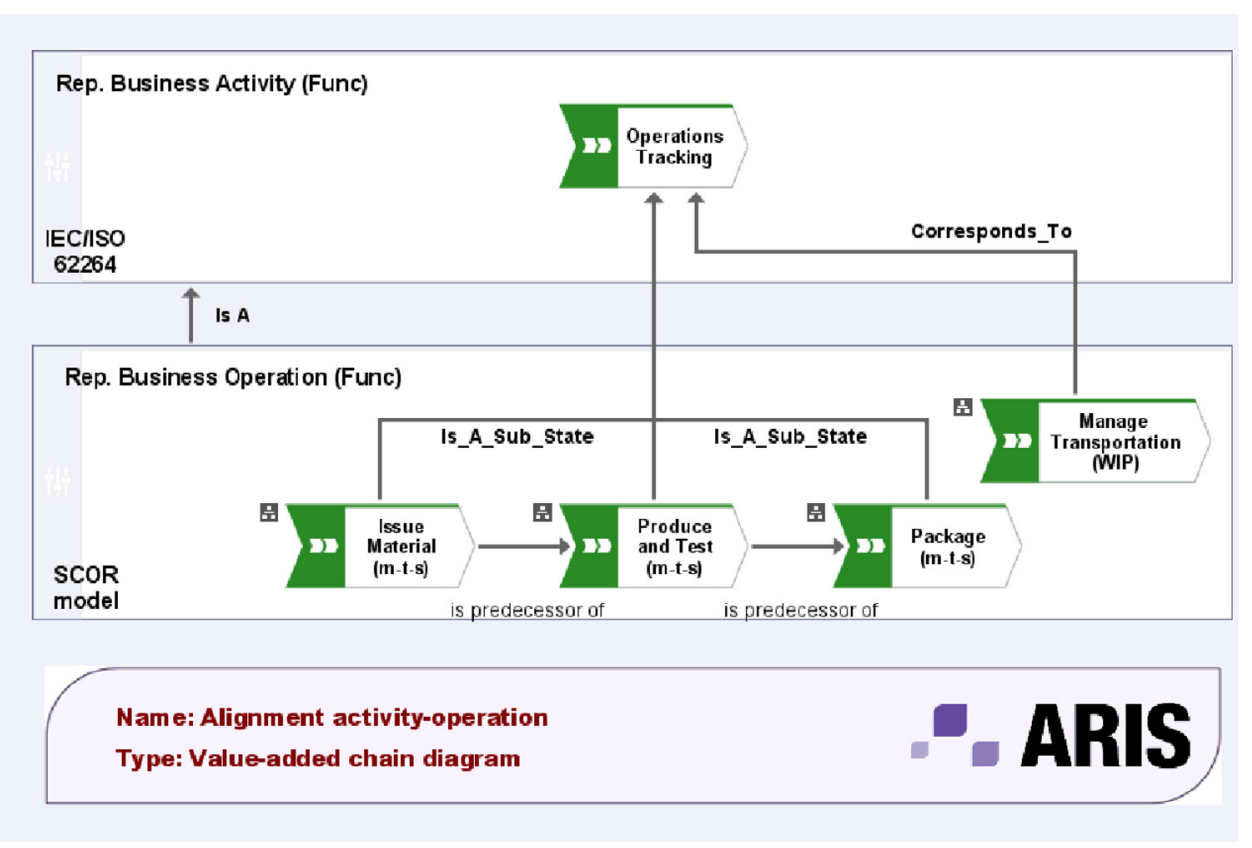

Fig. 2. Alignment at Functional Level Using Alignment Relationship.

Plan, Flow, and Journal) based on the results of Ref. [29]. This classification enables a first level of top-down alignment.

We therefore seek to provide a number of classes that is close enough and reasonable in comparison to the amount of information in ISO/IEC 62264. Table 3 shows the correspondence between the five information classes of the SCOR model and the nine information classes from the ISO/IEC 62264 repository.

To implement the alignment process on the ARIS platform, we initially create five IE data models including SCOR information (top-down approach). This alignment is reflected on ARIS using an association relationship between a cluster - representing one of the nine models of objects - and one (or more) model(s) of the IE data - representing one or more SCOR information classes. For example, the "Plan" and "Flow" classes are modelled using two "IE data models" having an association relationship with the "Operations Schedule" object model represented by a cluster.

We complete the semantic alignment with a bottom-up approach, starting from the lowest level, i.e. directly from I/O of the SCOR model "MAKE" process. For example, we align the elements of the "Resources" class with "Common Object" and "Operation Capability" information (Table 3). The results of this unidirectional alignment are:

- Some information remains out of the area despite the extraction step (i.e. information on supply chain performance, historical payroll, etc.).

- We identify two types of relationship between the elements of ISO/IEC 62264 and those of the SCOR model:

- A link of the 1.1 type: information from the SCOR model corresponds to a single object from the ISO/IEC 62264 repository. In this case, the two objects potentially have the same level of granularity and are "equivalent" from a semantic point of view.

- A link of the 1.N type: information from the SCOR model corresponds to one or more objects from the ISO/IEC 62264repository. We no longer have the same level of granularity. In this case, the information from the SCOR model is composite. For example, the "Production Orders Planned \& Actual Reports" information is composed of (Is_Composed_Of relathionship) "Operations Capability" and "Operations Performance" objects Functional view.

The ISO/IEC 62264 standard defines management models for manufacturing operations that allow the integration of enterprise control systems. Each model is a set of eight activities that act between the planning functions and the process control functions. Concerning the functions defined in the MAKE process of the SCOR model, we identify 28 functions. We keep the same alignment process as the one followed in the informational view, i.e. we start with a high level of abstraction to facilitate the alignment. We thus use the classification functions offered by the SCOR model, which consists in defining four variants for the MAKE process, corresponding to different business typologies: Make-to-Stock (MTS), Make-to-Order (MTO) Engineer-to-Order (ETO) and Enable-Make (EM). Table 4 shows a first level of the unidirectional alignment between the functions of the SCOR model (lines) and the activities of the repository $\mathrm{V}_{\mathrm{i}}$ (columns).

In this alignment step, which addresses the dimension of the granularity, we highlight the strong appearance of the perspective dimension between the two repositories. In fact, we try to align

Table 3

High-level informational alignment between SCOR and IOS 62264 .

\begin{tabular}{|c|c|}
\hline SCOR Information Classes & ISO/IEC 62264 Information Classes \\
\hline Resources & Common Object, Operation Capability \\
\hline Object & Operation Definition \\
\hline Plan & Operation Schedule, Operation Capability \\
\hline Flow & Operation Schedule, Operation Capability, Operation Performance \\
\hline Journal & Operation Schedule, Operation Capability, Operation Performance \\
\hline
\end{tabular}


Table 4

High-level functional alignment between the MAKE process and ISO/IEC 62264 activities.

\begin{tabular}{|c|c|c|c|c|c|c|c|c|}
\hline & Resource Management & Definition Management & Dispatching & Tracking & Data Collection & Analysis & Detail Scheduling & Execution Management \\
\hline MTS & $\times$ & & $x$ & $\times$ & & & $\times$ & $\times$ \\
\hline MTO & $\times$ & & $\times$ & $x$ & & & $\times$ & $\times$ \\
\hline ETO & $\times$ & $\times$ & $\times$ & $\times$ & & & $\times$ & $\times$ \\
\hline EM & $\times$ & $\times$ & $\times$ & $\times$ & $\times$ & & $\times$ & $\times$ \\
\hline
\end{tabular}

four processes with eight activities. In Table 4 the boxes are completed based on the textual description of each sub-process. This step requires the expert intervention to interpret the semantics and imagine the potential activities of the standard that may have a relationship with each process. Here we start from the lowest level of the MAKE process, i.e. the functions of the variant processes, and thus align the 28 functions of SCOR on the eight of the ISO/IEC 62264 activities. We have thus identified two functions outside the area: risk management, and management of the regulatory environment. We also identified two kinds of links: a 1.1 type link "is equivalent to" which corresponds to elements with same level of granularity and perspective, and a 1.N type link "is the master of". In the latter case, the functions of SCOR model have a higher granularity level than the activities of the repository $\mathrm{V}_{\mathrm{i}}$, and secondly, they all present process elements.

Table 5 shows the different possible alignment situations that experts may encounter in the alignment process, and the names of corresponding relationships.

\subsection{Validation cycle by business experts}

Human expertise is required in our alignment process. The goal is to align the two repositories at a level of granularity close to each other. The top-down approach of informational semantic alignment significantly reduces the number of potential mapping operations between elements. However, in the bottom-up alignment, the expert has to solve semantic interpretations of differences between repositories. For example, he/she must take into account the process approach of the SCOR model, which is absent in the ISO/IEC 62264, or to exclude the risk management used in the SCOR model, which is not required in the repository $\mathrm{V}_{\mathrm{i}+1}$.

So, the repository $V_{i+1}$ is submitted for validation to multiple business experts, including experts on ISO/IEC 62264 and on the SCOR model. We have proposed a refinement cycle attended by experts, to resolve semantic conflicts due to the interpretation of the semantic models, objects and business processes, which vary from one expert to another. As mentioned in Section 3.1, we faced different situations at the pragmatic heterogeneity level where various experts interpret the semantics of the two repositories. The choice to perform a unidirectional alignment (to the ISO/IEC 62264) guarantees the convergence of experts' alignments.

To facilitate the experts' decision-making, we have developed some semantic control rules to check and detect semantic inconsistencies of new additional elements. In Fig. 3, we assume that we have one element of information $\mathrm{X}$ and two activities $\mathrm{B}$ and C from the ISO/IEC 62264, such that " $\mathrm{X}$ is the input of $\mathrm{B}$, not of C". Suppose that the information $\mathrm{X} 1$ and function $\mathrm{C} 1$ are two variants of the SCOR model, respectively of information $\mathrm{X}$ and activity $\mathrm{C}$, such that "X1 is the entry of C1". The semantic check detects an inconsistency, even if the relationship between $\mathrm{X} 1$ and $\mathrm{C} 1$ is well defined in SCOR. The role of the business expert is to make a decision about this relationship:

- The alignment of the two entities X1 and C1 of the SCOR model on, respectively, $\mathrm{X}$ and $\mathrm{C}$ is false. In this case, it is necessary to correct or to delete one or both of these variant relationships.

- The alignment is correct. The expert validates the repository $V_{i+1}$ despite this apparent inconsistency.

- The defined semantic control rule does not apply in some cases.

Table 6 shows an excerpt of a report presenting results for semantic control applied to a business scenario: "Scheduling and launching of a Production Order in job shop". The same semantic control rule may be applied directly to the models.

\section{Evaluation and key lessons learned}

\subsection{Evaluation}

The benefit assessment of this work is evaluated using the Enterprise Architecture Maturity Model of Ref. [38], based on a set of best practices. It contains Maturity Levels ranging from 1 to 5 , depending on the best practices integration levels. We have considered Nascio's best practices, which are clearly in relation with our proposal, excluding issues like administration, planning or communication. We focused on the following best practices regarding standards, processes and models to evaluate the contribution of our methodology:

- Framework to organize processes and templates used for Enterprise Architecture (EA)

- Blueprint as collection of the actual standards and specifications

- Compliance, to evaluate the adherence to published standards, processes and other EA elements, and the processes to document and track variances from those standards

- Integration to evaluate consistency of management processes with EA

We evaluated retrospectively the required level of maturity and the potential contribution of our alignment methodology, to reach

Table 5

Implementation in ARIS modelling language of alignment relationships.

\begin{tabular}{|c|c|c|c|}
\hline & Views & Situation & Semantic relation created to model the alignment \\
\hline Granularity & $\begin{array}{l}\text { Informational View } \\
\text { Functional View }\end{array}$ & $\begin{array}{l}\text { ISO } / \text { IEC } 62264=S C O R \\
\text { ISO/IEC } 62264<\text { SCOR } \\
\text { ISO } / \text { IEC } 62264=\text { SCOR } \\
\text { ISO } / \text { IEC } 62264>\text { SCOR } \\
\text { ISO } / \text { IEC } 62264<\text { SCOR }\end{array}$ & $\begin{array}{l}\text { Variant } \\
\text { "is composed of" } \\
\text { "is equivalent to" } \\
\text { "belongs to" } \\
\text { "is master of" }\end{array}$ \\
\hline Perspective & Functional View & & "is predecessor of" \\
\hline
\end{tabular}




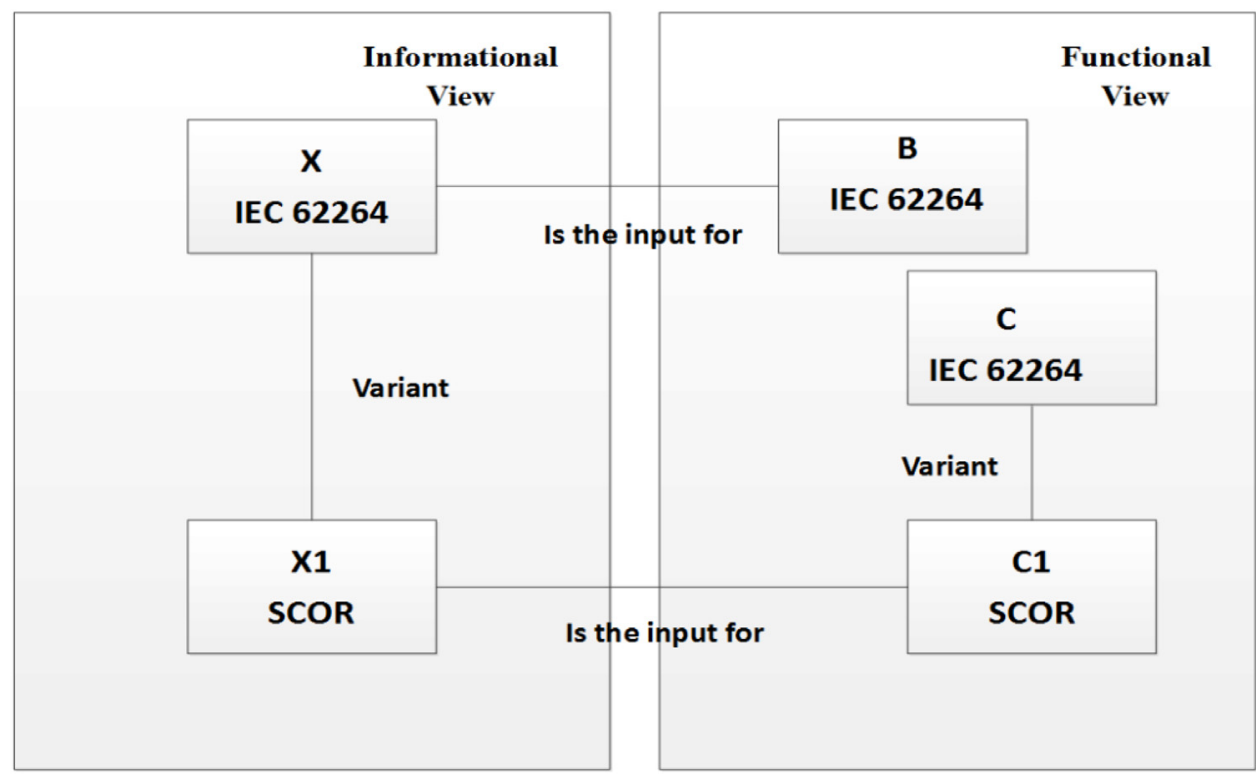

Fig. 3. Example of semantic inconsistency.

Table 6

Semantic control report with comments on ISO 62264 compliance.

\begin{tabular}{|c|c|c|}
\hline \multicolumn{3}{|l|}{ Bring the tools } \\
\hline Cluster 1: Workshop Chief & $\begin{array}{l}\text { The object "Workshop Chief" has a master in the repository associated to the master of the } \\
\text { function. }\end{array}$ & $\begin{array}{l}\text { The ISO } 62264 \text { standard is complied } \\
\text { with. }\end{array}$ \\
\hline Cluster 2: Hand Tools & The object "Hand Tools" & $\begin{array}{l}\text { The ISO } 62264 \text { standard is complied } \\
\text { with. }\end{array}$ \\
\hline \multicolumn{3}{|c|}{ Print the inventories for a production order } \\
\hline Cluster 1: Workshop Chief & $\begin{array}{l}\text { The object "Workshop Chief" has a master in the repository associated to the master of the } \\
\text { function. }\end{array}$ & $\begin{array}{l}\text { The ISO } 62264 \text { standard is complied } \\
\text { with. }\end{array}$ \\
\hline \multicolumn{3}{|c|}{ Verify availability of material for a production order } \\
\hline $\begin{array}{l}\text { Cluster 2: Document of a production } \\
\text { order }\end{array}$ & $\begin{array}{l}\text { The object "Workshop Chief" has a master in the repository associated to the master of the } \\
\text { function. }\end{array}$ & $\begin{array}{l}\text { The ISO } 62264 \text { standard is complied } \\
\text { with. }\end{array}$ \\
\hline
\end{tabular}

new levels of maturity regarding each of these best practices (Table 7).

Obviously, the objective of mastering heterogeneity through alignment of different business models requires the processes to be planned and tracked, and the organization to be able to reuse methods for capturing critical $\mathrm{E}$ information (Level 2/Framework). Our methodology reaches three of the four characteristics expected for Level 3. The architecture based on the resulting repository $\mathrm{V}_{\mathrm{i}+1}$ helps the industrial company to customize the processes in a specific/local context, to prepare process models, and to use templates. The last characteristic regarding processes' lifecycles is not considered.

Regarding the blueprint, a prerequisite is that technology standards are documented (Level 1). Using our proposal to build a MES repository able to integrate other heterogeneous business

Table 7

A contribution of levels of maturity.

\begin{tabular}{lll}
\hline Best Practices & Required Level & Contribution to upper level \\
\hline Framework & Level 2 & $3 / 4$ of Level 3 \\
Blueprint & Level 1 & Level 3 \\
Compliance & Level 1 & $2 / 3$ of Level 3 \\
Integration & Level 2 & $1 / 2$ of Level 3 \\
\hline
\end{tabular}

models is an opportunity to build an enterprise architecture repository to ensure consistency of documentation (Level 3).

Compliance of processes and procedures with standards is a core characteristic of our methodology. A clear requirement is the need for compliance with standards to be identified, even if the compliance is informal and unstructured, and cannot be measured effectively, because processes and procedures are not consistent across areas and/or projects (Level 1). The result of a MES project using our proposal is that the company has begun to develop a compliance process to ensure consistency with Enterprise Architecture standards (Level 2). Furthermore, it is a driver to organize a formal compliance process as an integral part of the enterprise architecture lifecycle processes, consistently throughout the enterprise (Level 3). It can help to ensure that a Business Case is required for variance from the standards.

Finally, regarding integration, the use of a repository implies that the need to document common functions has been identified, even if MES projects are carried out in isolation (Level 1). In addition, it implies that the need for integration of processes in the EA Framework has been identified, even if the various touch-points between the management processes and the EA Program Framework have been mapped, without details on how the integration works. This is an intermediate situation between level 1 and level 2 . Our methodology helps to define consistently the 
relation of management processes to the enterprise architecture, even without any strategic planning and budgeting processes (level 3).

The main contributions of our proposal to enterprise maturity using models in enterprise architecture is the role of the repository obtained in the enhancement of business capabilities and processes documentation (i.e. Blueprint), and consequently in the capacity to evaluate compliance with standards.

\subsection{Key lessons learned from the case study}

The Business Repository based on ISO 62624 and enriched with different business knowledge is built to be used by an industrial company to ensure that their business objects and processes are "standard compliant". The objectives are to ensure the consistency of the MES information system and to reduce the cost of its implementation in on-demand solutions. This has been done by integrating our repository into the platform of the consortium [39]. This platform offers orchestration of MES services based on the partners' existing applications [40].

The evaluation of our repository used various business cases proposed by the software publishers involved in the platform. Each of these cases was modelled using standard business objects and functions from the repository, irrespective of their source functions, or from SCOR model, ISO/IEC 62264, or software publishers. This demonstrates the capacity of the MES repository obtained to allow the modelling of actual business cases in a user perspective, using heterogeneous repositories.

Based on this case study, we propose an alignment methodology to allow the use of experts' knowledge, using the repository as a decision support tool for semantic alignment.

To take into account the variety of alignment situations, depending on granularity, perspective or coverage of repositories, we formalized the alignment results by listing semantic relationships between the different elements of both business repositories.
Fig. 4 shows the meta-model for semantic alignment of the SCOR model on ISO/IEC 62264.

These alignment relations are a first approach of a meta-model of alignment to extend a modelling platform as an alignment tool.

\section{Conclusions}

In this paper, we develop a unidirectional approach to align business repositories for enriching a core-business repository. The approach consists of four steps: comparison, modelling, alignment and validation. This comparison is based on four levels of heterogeneity: syntactic, terminological, conceptual and pragmatic. On each of these levels, different situations of alignment, regarding granularity, views, or consistency, serve to classify different alignment relationships, and then to define an enrichment-based alignment approach for business repositories. This approach uses semantic control rules that allow experts to check the consistency of alignment decisions.

We assess the contribution of this approach to enterprise maturity in the use of standards and reference models when experts are dealing with heterogeneity in the context of modeldriven projects and have to evaluate the compliance of their enriched models with standards.

This new approach helps experts in the management of semantic heterogeneities between business repositories, as experimented with through the integration of parts of the SCOR model in the ISO/IEC 62246 repository.

Firms can use this approach to comply with a standard repository when expressing their requirements and to ensure a reliable implementation using standard components. For software publishers, this "on-demand" approach is a key success factor to be selected in companies' projects.

Further research could be done to build indicators of alignment levels between repositories, based on the meta-model and rules. Such indicators could give the actors of a MES project (firms,

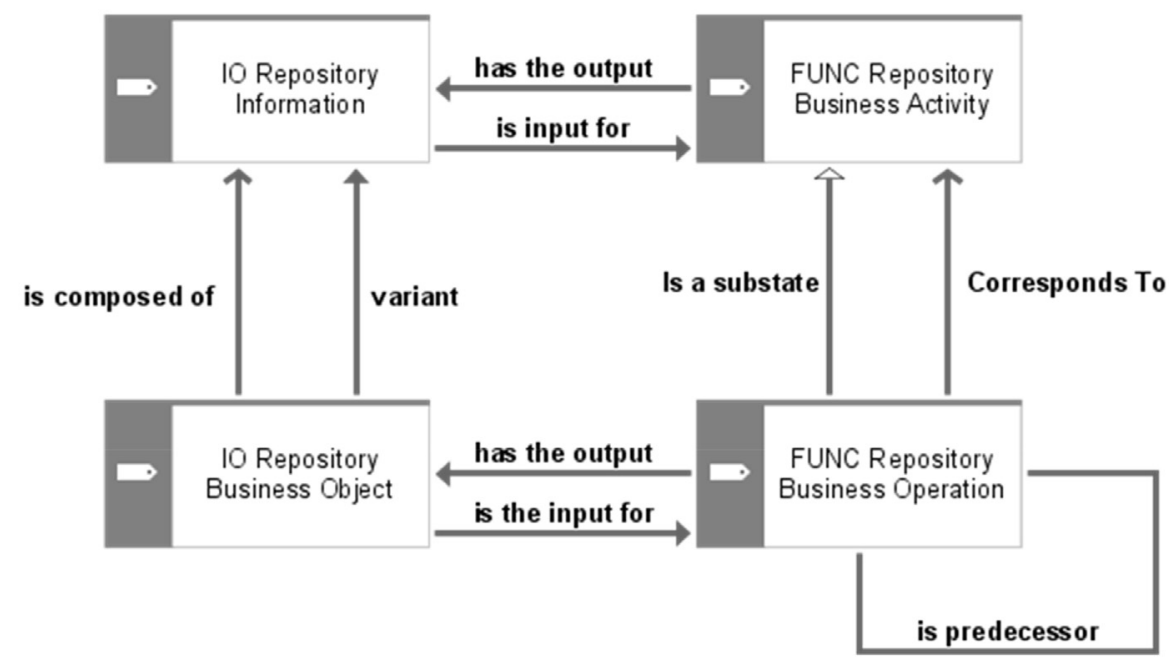

Name: meta-model of alignment

Type: Technical terms model

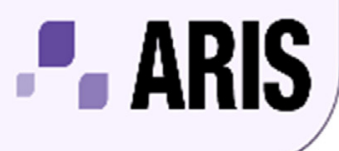

Fig. 4. Meta-model for semantic alignment between business repositories. 
publishers, and experts) an overall view of the alignment, in relation to the project's progress and at different levels of granularity, so as to facilitate decisions on a greater or lesser degree of integration.

\section{Acknowledgments}

This research was part of a research project funded by FEDER and the Région Rhône-Alpes (France), involving a consortium of eight editors of MES solutions.

\section{References}

[1] F.B. Vernadat, Enterprise Modeling and Integration: Principles and Applications, Chapman \& Hall, London, UK, 1996496 p. ISBN: 978 0412605505.

[2] C.H. Goh, Representing and Reasoning about Semantic Conf licts in Heterogeneous Information Sources". Thèse de doctorat, Massachusetts Institute Of Technology, Massachusetts, 1997113 p..

[3] C. Bussler, Semantic Web services: reflections on Web se rvice mediation and composition, Proceedings of the Fourth International Conference on Web Information Systems Engineering, Galway, Ireland, 2003, pp. 253-260.

[4] S.M. Falconer, N.F. Noy, M.A. Storey, Towards understanding the needs of cognitive support for ontology mapping, Proc Ontology Matching Workshop (2006) 25-36.

[5] M., Klein, Combining and relating ontologies: an analysis of problems and solutions., in Proceedings of Workshop on Ontologies and Information Sharing at the 17th International Joint Conference on Artificial Intelligence (IJCAI2001), G.A. Perez, H.H. Gruninger, H. Stuckenschmidt, M. Uschold, Editors. 2001: Seattle, WA, USA.

[6] W. Hasselbring, Information system integration, Commun. ACM 43 (6) (2000) 33-38.

[7] European Interoperability Framework for pan - European eGovernment Services, Interoperable Delivery of European eGovernment Services to public Administrations, Businesses and Citizens (IDABC),. Rapport de recherche $\mathrm{n}^{\circ}$ 1.0: Luxembourg: 2004, $26 \mathrm{p}$.

[8] MESA, 1997. https://services.mesa.org/ResourceLibrary/ShowResource/ 2cedfe75-daed-4b9c-b187-f421cf90fdd2.

[9] H. Guangke, H. Weiping, H. Yanli, Y. Hui, Research on reconfigurability of service-oriented manufacturing execution system, IEEE 10th International Conference on Computer - Aided Industrial Design \& Conceptual Design, 2629 Nov (2009).

[10] D.U. Saenz, A. Artiba, R. Pellerin, Manufacturing execution system - a literature review, Prod. Plann. Control J. 20 (6) (2009) 525-539.

[11] J.A. Vinhasis, Manufacturing execution systems: the one-stop information source, Qual. Digest 18 (9) (1998) 39-40.

[12] B. Hakanson, MES stands for manufacturing improvements, IIE Solut. 28 (2) (1996) 26-29.

[13] D.J. Adler, J. Herkamp, D. Henricks, R. Moss, Does a manufacturing execution system reduce the cost of production for bulk pharmaceuticals? ISA Trans. 34 (4) (1995) 343-347.

[14] J.-S. Ulmer, A pivotal-based approach for enterprise business process and IS integration, Enterp. Inf. Syst. (EIS) 7 (1) (2013) 61-78.

[15] G. Doumeingts, B. Vallespir, D. Chen, GRAI grid decisional modelling, in handbook on architecture of information systems, in: P. Bernus, K. Mertins, G. Schmith (Eds.), Handbook on Information Systems, Springer Verlag, Berlin, 1998, pp. 313-337.

[16] C. Braesch, F. Théroude, A. Haurat, OLYMPIOS: a model to control by process reengineering, International Conference Systems Engineering and Information \& Communication Technology (TIC'2000), Nîmes, France, 2000.
[17] M. Zelm, F.B. Vernadat, K. Kosanke, The CIMOSA business modelling process, Comput. Ind. 27 (2) (1995) 123-142.

[18] K. Kosanke, J.G. Nell, Enterprise Engineering and Integration: Building International Consensus, Springer-Verlag, Torino, Italy, 1997 pp. 634.

[19] A.-W. Scheer, K. Schneider, ARIS-architecture of integrated information systems, in: P. Bernus, K. Mertins, G. Schmidt (Eds.), Handbook on Architectures of Information Systems, Springer, Berlin Heidelberg, 2006, pp. 605-623 ISBN: 978-3-540-26661-7.

[20] K. Medini, J.P. Bourey, SCOR-based enterprise architecture methodology, Int. J. Comput. Integr. Manuf. (IJCIM) 25 (7) (2012) 594-607.

[21] CEN, ENV 12204: Advanced Manufacturing Technology - Systems Architecture - Constructs for E nterprise Modelling, (1996) 44 p..

[22] ISO, ISO 15704: Industrial Automation Systems - Requirements for Enterprisereference Architectures and Methodologies, (2000) 43 p..

[23] ISO/TC and CEN/TC, "Enterprise integration - Framework for enterprise modelling (ISO 19439)". 2006, $47 \mathrm{p}$.

[24] ISO/TC, "DRAFT INTERNATIONAL STANDARD ISO/DIS 19440". Enterprise integration - Constructs for enterprise modelling, 2004, $63 \mathrm{p}$.

[25] ISO/IEC-1, "IEC 62264-1: Enterprise-control system integration". Part 1: Models and terminology, 2003, $128 \mathrm{p}$.

[26] ISO/IEC-2, "IEC 62264-2: Enterprise-control system integration". Part 2: Model object attributes, 2004, $96 \mathrm{p}$.

[27] ISO/IEC-3, "IEC 62264-3: Enterprise-control system integration". Part 3: Activity models of manufacturing operations management, 2007, $212 \mathrm{p}$

[28] Supply Chain Council, Supply Chain Operations Reference Model (SCOR) Version 10.0 [online], (2010) Available from: http://supplychain.org/scor/10.0 (Accessed 02 June 2015).

[29] P.-A. Millet, An Analysis of Organizational and Informational Integration. Application to ERP Based Information Systems. Thèse De Doctorat, INSA de Lyon, Lyon, 2008308 p..

[30] M.Zdravković, M. Trajanović, H. Panetto, M. Lezoche, A. Aubry, Ontology-based supply chain process configuration, in: M. Trajanović (Ed.), In Proceedings of the 34th International Conference on Production Engineering, Niš, Serbia, 2011, pp. 399-402.

[31] G. Stewart, Supply-chain operations reference model (SCOR): the first crossindustry framework for integrated supply-chain management, Logist. Inf. Manage. 10 (2) (1997) 62-67.

[32] Y.-D. Hwang, Y.-C. Lin, L.J. Jung, The performance evaluation of SCOR sourcing process - the case study of Taiwan's TFT - LCD industry, Int. J. Prod. Econ. 115 (2) (2008) 411-423.

[33] P.-A. Millet, P. Schmitt, V. Botta-Genoulaz, The SCOR model for the alignment of business processes and information systems, Enterp. Inf. Syst. 3 (4) (2009) 393-407.

[34] ISO, ISO 10303: Industrial automation systems and integration Product data representation and exchange - Overview and Fundamental Principles. ISO TC184/SC4, 1994, 17 p.

[35] R., Tricker, "ISO 9001 :2000 : The Quality Management Process": Van Haren Pub, 2006, 186 p. (B. Practice).

[36] KnowledgeWeb, 2004. Deliverables of KWEB Project EU-IST-2004-507482. Research report.

[37] WBF, "B2MML". Available at: <http:// http://www.mesa.org/en/B2MML.asp> (Accessed 07 September 2016).

[38] National Association of State Shief Information Officers, NASCIO Enterprise Architecture Maturity Model [online], (2003) Available from: http://www. nascio.org/publications/documents/NASCIO-EAMM.pdf [Accessed July 2015].

[39] AGILIUM, "Le trophée du LABEL MESTRIA", http://www.agilium.com/spip. php? page $=$ article\&id_article $=184 \&$ connect=awensys. Accessed 07 September 2016.

[40] H. Verjus, MESTRIA: Le Pilotage d'Atelier à La Carte, (2011) Available from: http://www.jiteconline.com/mestria__le_pilotage_d_atelier_a_la_cartefr1827.html. Accessed 07 September 2016.

[41] M. Larson, Gain shop-floor control with MES software, Quality 36 (6) (1997) 68-70. 